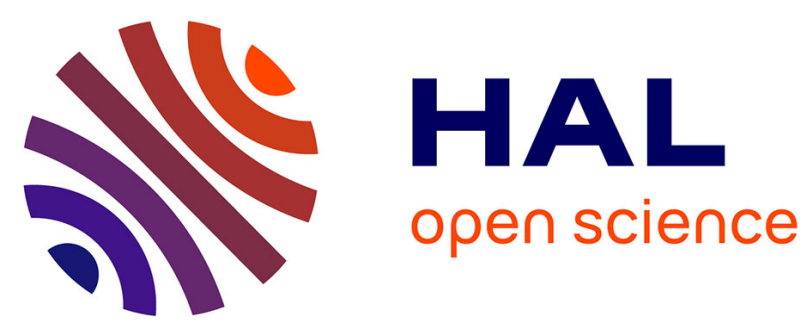

\title{
New polyurethanes based on diphenylmethane diisocyanate and 1,4:3,6-dianhydrosorbitol, 1. Model kinetic studies and characterization of the hard segment
}

Estelle Cognet-Georjon, Françoise Méchin, Jean-Pierre Pascault

\section{- To cite this version:}

Estelle Cognet-Georjon, Françoise Méchin, Jean-Pierre Pascault. New polyurethanes based on diphenylmethane diisocyanate and 1,4:3,6-dianhydrosorbitol, 1 . Model kinetic studies and characterization of the hard segment. Macromolecular Chemistry and Physics, 1995, 196 (11), pp.3733-3751. 10.1002/macp.1995.021961125 . hal-02045986

\author{
HAL Id: hal-02045986 \\ https://hal.science/hal-02045986
}

Submitted on 4 Mar 2020

HAL is a multi-disciplinary open access archive for the deposit and dissemination of scientific research documents, whether they are published or not. The documents may come from teaching and research institutions in France or abroad, or from public or private research centers.
L'archive ouverte pluridisciplinaire HAL, est destinée au dépôt et à la diffusion de documents scientifiques de niveau recherche, publiés ou non, émanant des établissements d'enseignement et de recherche français ou étrangers, des laboratoires publics ou privés. 


\title{
New polyurethanes based on diphenylmethane diisocyanate \\ and 1,4:3,6-dianhydrosorbitol, 1 \\ Model kinetic studies and characterization of the hard segment
}

\author{
Estelle Cognet-Georjon, Françoise Méchin \& Jean-Pierre Pascault \\ Laboratoire des Matériaux Macromoléculaires, URA CNRS 507, \\ Institut National des Sciences Appliquées de Lyon, Bât. 403, \\ 20, avenue Albert Einstein, 69621 Villeurbanne Cedex, France
}

\section{SUMMARY:}

1,4:3,6-Dianhydrosorbitol (DAS) seems to be an interesting reagent for the synthesis of polyurethanes. In the present work, the kinetics of the reaction of DAS with a monoisocyanate ( $p$-tolyl isocyanate, $\mathrm{p}$ $\mathrm{TI})$ and with a diisocyanate $\left(4,4^{\prime}\right.$-diphenylmethane diisocyanate, $\left.\mathrm{MDI}\right)$ were studied with the help of a chromatographic method (size exclusion chromatography, SEC). When the condensation reaction is performed in tetrahydrofuran (THF) solution, with dibutyltin dilaurate (SnDBDL) as catalyst, DAS exhibits two equireactive hydroxyl groups. The reaction rate can be well described by a second-order equation modified to include catalysis by the formed urethane functions. MDI and DAS were then condensed using two different experimental procedures (bulk and solution polycondensation in THF, in the presence of SnDBDL), and the characteristics of the resulting polyurethanes were compared. Bulk polycondensation led to an amorphous polymer, whereas the polyurethane prepared in solution was semi-crystalline. In both cases, we obtained a very high glass transition temperature $\left(\approx 186^{\circ} \mathrm{C}\right)$. The synthesis of samples with various polymerization degrees gave a better understanding of the molecular weight distribution of segmented polyurethanes based on MDI and DAS.

Published in Macromolecular Chemistry \& Physics, vol. 196, 3733-3751 (1995) 


\section{Introduction}

Over the past few years, many studies have been made in the field of polymer synthesis in order to find substitution products for those derived from oil-based chemistry. Among other possible reactants, 1,4:3,6-dianhydrosorbitol (DAS), which has previously been used for its chemical ${ }^{11}$ and pharmaceutical properties, is an interesting candidate: it exhibits chemical and thermal stability ${ }^{2}$, has two hydroxyl groups and is available in industrial quantities from starch. In recent works, this monomer has found application in the synthesis of technical polymers. Thiem and Lüders ${ }^{3,4}$ were the first to report the study of the synthesis and characterization of polyesters deriving from terephthaloyl dichloride and DAS; these polyesters, as well as polyurethanes prepared some time after ${ }^{5)}$, exhibited low molecular weights $\left(\overline{M_{n}}=3000\right)$. More recent works on polyesters ${ }^{6,7)}$, polycarbonates, polyurethanes ${ }^{7)}$ and polyamides ${ }^{8)}$ mention higher molecular weights.

In this paper, we report the kinetic investigation of the reaction between a model monofunctional aromatic isocyanate, ( $p$-tolyl isocyanate, $\mathrm{p}$-TI) and the hydroxyl functions of DAS; the results have been applied to the preparation of polyurethane hard segments based on DAS and a classical aromatic diisocyanate, 4,4'-diphenylmethane diisocyanate $(\mathrm{MDI})^{\mathrm{a})}$. Two polycondensation methods were compared: bulk and solution polycondensation in THF in the presence of little amounts of a catalyst (dibutyltin dilaurate, SnDBDL). The thermal properties of the resulting polymer have then been characterized and compared to those of classical hard segment moieties for segmented polyurethanes.

\section{Experimental part}

\section{Materials}

1,4:3,6-Dianhydrosorbitol (or isosorbide, DAS) was a gift from Roquette Frères. It was recrystallized from methyl ethyl ketone and then dried in vacuo $(0.1 \mathrm{mbar}) . p$-Tolyl isocyanate was purchased from Aldrich, whereas 4,4'-diphenylmethane diisocyanate (MDI) was a gift from Bayer AG; both isocyanates were used without further purification. Dibutyltin dilaurate (SnDBDL, Merck) was also used as received.

\section{Kinetic studies}

The reactions were carried out in a $500 \mathrm{~mL}$ round-bottom flask equipped with a magnetic stirrer and a reflux condenser, under inert atmosphere. DAS $(0.05 \mathrm{~mol})$ together with the isocyanate $(p-\mathrm{TI}, 0.05$ or $0.1 \mathrm{~mol}$ or $\mathrm{MDI}, 0.05 \mathrm{~mol}$ ) were dissolved in tetrahydrofuran (THF, $200 \mathrm{~mL}$ ). The reactor was then placed in a thermoregulated oil bath; after the solution had reached the desired reaction temperature $\left(50^{\circ} \mathrm{C}\right)$, the catalyst SnDBDL ( $0.15 \mathrm{wt} .-\%$ with respect to the whole weight of reagents) was added and the corresponding time was taken as the start of the reaction. Samples were pipetted at measured intervals and the $p$-TI or MDI contents were determined by size exclusion chromatography (SEC) using a Waters chromatograph equipped with a $6000 \mathrm{~A}$ pump, U6K injector, and 4 microstyragel columns. The eluent was THF, and the peak areas were calculated using refractometric detection ( $p$-TI) together with UV detection ( $\lambda=254 \mathrm{~nm}$, for systems based on MDI, since DAS and MDI have the same elution time but DAS does not absorb at this wavelength). Toluene (10 mL) in the case of $p$-TI, and diphenyl in the case of MDI were used as internal standards. The molecular weights were determined using a calibration curve established with polystyrene standards.

\footnotetext{
a) Systematic name: 4,4'-methylenebis(1,4-phenylene) diisocyanate.
} 


\section{Polyurethane synthesis}

\section{Bulk polycondensation}

In a reactor equipped with a mechanical stirrer and a nitrogen inlet, MDI and DAS were introduced in a stoichiometric ratio. The flask was then placed in a thermoregulated oil bath (temp. $=80^{\circ} \mathrm{C}$ ). When the mixture had reached an adequate viscosity, it was degassed under vacuum with continuous stirring. After $10 \mathrm{~min}$ the reacting mixture was poured onto a plate mould which was finally pressed at $200^{\circ} \mathrm{C}$ (100 bars) for $24 \mathrm{~h}$. The resulting polymer was transparent.

\section{Solution polycondensation}

The procedure was the same as that of kinetic studies. Various $[\mathrm{NCO}] /[\mathrm{OH}]$ ratios were used $(7 / 6,5 / 4$, $3 / 2$ and $1 / 1$ ). The reaction was carried out at $50^{\circ} \mathrm{C}$ in THF with SnDBDL as catalyst. Partial precipitation was often observed. After $3 \mathrm{~h}$, the polymer was precipitated in methanol, filtered and dried under vacuum (0.1 mbar). The resulting polymers are white powders.

\section{Polyurethane characterization}

Thermal properties

Melting and glass transition temperatures were determined by differential scanning calorimetry (DSC). Analyses were run on a Mettler TA 3000 apparatus under argon, using a heating rate of $7.5 \mathrm{~K} / \mathrm{min}$.

Nuclear magnetic resonance

'H NMR spectra were collected on a Bruker AC 200 apparatus (200 MHz) on deuterated DMSO solutions at $50^{\circ} \mathrm{C}$.

\section{Results and discussion}

\section{Model kinetic studies}

The structure of DAS is shown in Fig. $1^{99}$. Its stereochemistry has been described several times ${ }^{9-12)}$; the $\mathrm{OH}-2$ group is in the exo position, whereas $\mathrm{OH}-5$ is in the endo position on the bicyclic ring system. As both are secondary hydroxyl groups and thus not very reactive towards isocyanates, we chose aromatic isocyanates because of their greater reactivity compared to aliphatic or cycloaliphatic isocyanates.

In the case of DAS, two factors can affect the hydroxyl group reactivity. On the one hand, an intramolecular hydrogen bond between the endo hydroxyl group on $\mathrm{C} 5$ and the ring-oxygen atom between $\mathrm{C} 1$ and $\mathrm{C} 4$ can enhance the nucleophilic character of the $\mathrm{OH}-5$ function in comparison with the exo hydroxyl group on $\mathrm{C2}$. On the other hand, the steric hindrance decreases the reactivity of the $\mathrm{OH}-5$ group. Because of these different steric surroundings, and although numerous works regarding the reaction between alcohols and isocyanates had already been published, the reactivity of DAS towards a model monofunctional aromatic isocyanate $(p$-TI) was first investigated. The respective reactivities of $\mathrm{OH}-2$ and -5 can actually be very different depending on the co-reactant and on the reaction conditions ${ }^{10,12-17)}$. 


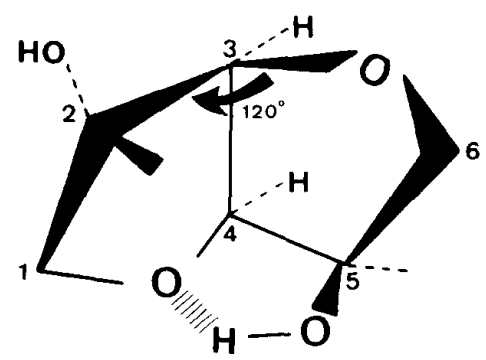

Fig. 1. Spatial structure of DAS (from ref. ${ }^{9}$ )

The reaction between DAS and $\mathrm{p}-\mathrm{TI}$ can be described by the following scheme:

Scheme 1: Formation of the diurethane DiU with monourethanes MonoU2 (first reacted hydroxyl group $=\mathrm{OH}-2$ ) and MonoU5 as intermediates

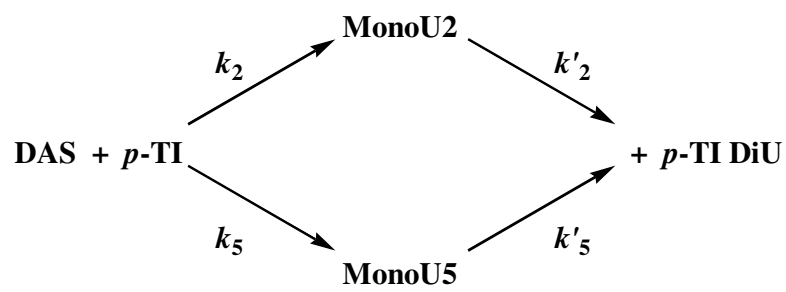

If the reaction of the first hydroxyl group on the DAS molecule does not modify the reactivity of the second one (i.e. if there is no substitution effect), then $k_{2}^{\prime}=k_{5}$ and $k_{5}^{\prime}=k_{2}$. If in addition both functions are equireactive, then $k_{2}=k_{5}$.

Fig. 2 depicts the evolution with time of the SEC chromatograms obtained during the reaction of DAS with $p-\mathrm{TI}(\mathrm{NCO} / \mathrm{OH}=1)$. This technique did not allow to separate the intermediates MonoU2 and 5.

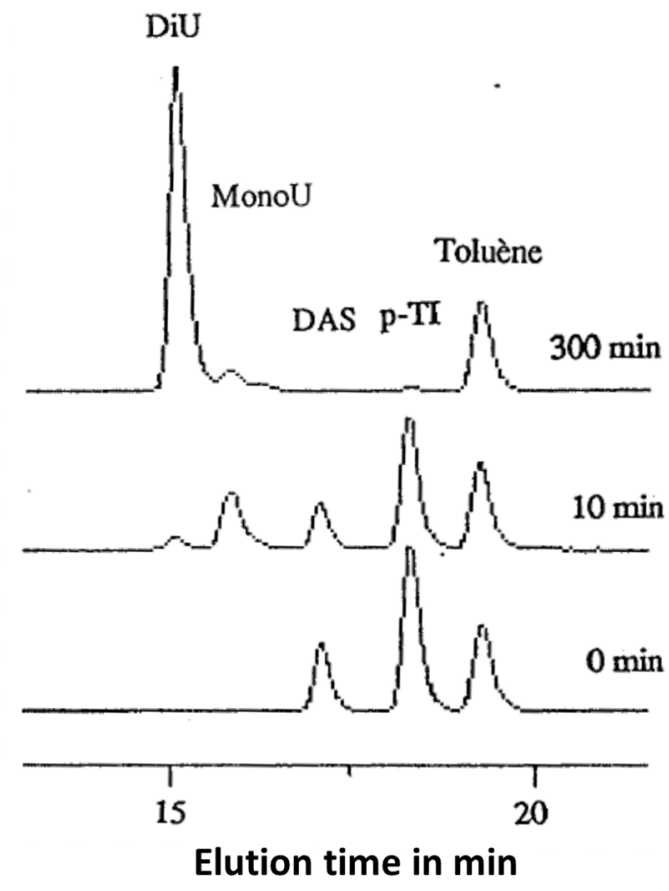

Fig. 2. Various SEC chromatograms obtained during the reaction of DAS with $p$-TI (THF solution, temp. $=50^{\circ} \mathrm{C}$, catalyst $=$ dibutyltin dilaurate) (refractometric detection) 
The disappearance of the monomers can be expressed in the following way:

$$
X_{t}=\frac{[\mathrm{DAS}]_{t}}{[\mathrm{DAS}]_{0}} ; A_{t}=\frac{[p-\mathrm{TI}]_{t}}{[p-\mathrm{TI}]_{0}}
$$

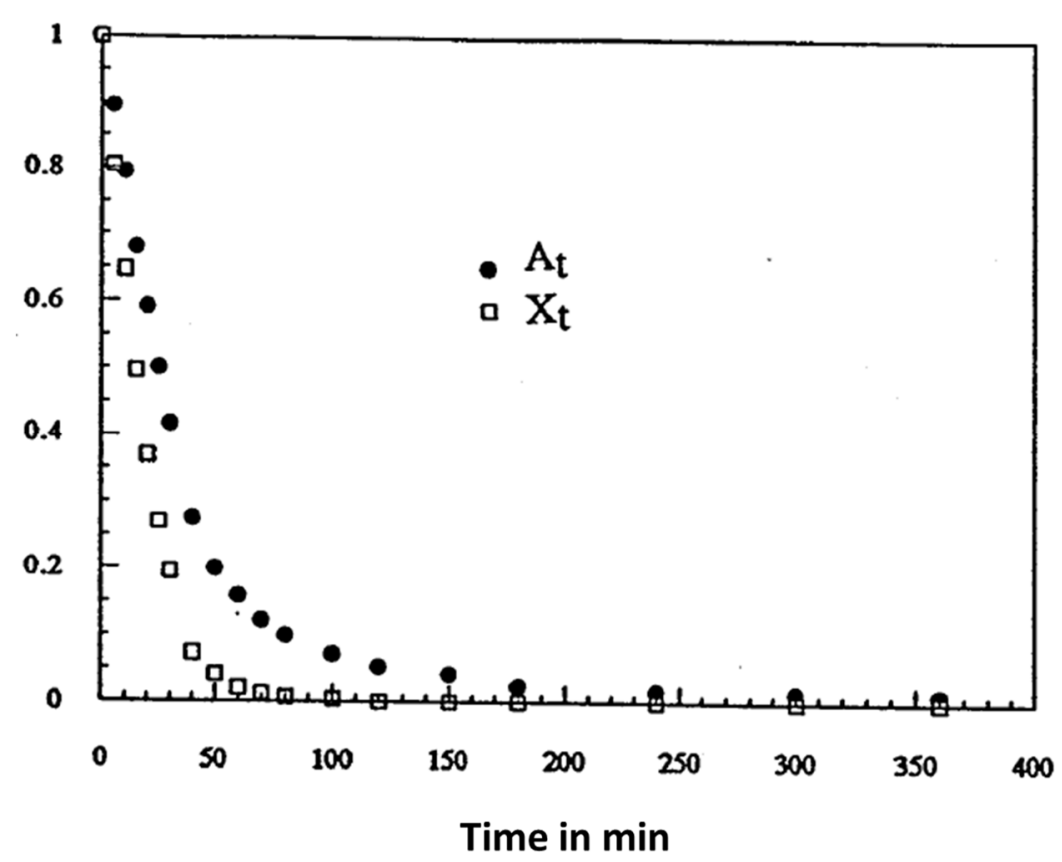

Fig. 3. Decrease in the concentration of DAS and $\mathrm{pTI}$ with time at $50^{\circ} \mathrm{C}$ (THF solution, catalyst $=$ $\operatorname{SnDBDL}) ;(O): A_{t}=\frac{[p-T I]_{t}}{[p-T I]_{0}} ;(\square): X_{t}=\frac{[D A S]_{t}}{[D A S]_{0}}$

where [DAS] and $[p-\mathrm{TI}]$ stand for the concentrations of the corresponding monomers (dihydroxyl compound and monoisocyanate) expressed in $\mathrm{mol} / \mathrm{kg} ; X$ and $A$ can be calculated from the areas of the peaks in the SEC chromatograms. Fig. 3 shows the variation of $X_{t}$ and $A_{t}$ with time at $50^{\circ} \mathrm{C}$ in THF; total conversion is reached after about $5 \mathrm{~h}$.

As $p-\mathrm{Tl}$ is a monofunctional monomer, $A_{t}=\frac{[p-\mathrm{TI}]_{t}}{[p-\mathrm{TI}]_{0}}=\frac{[\mathrm{NCO}]_{t}}{[\mathrm{NCO}]_{0}}$. As for hydroxyl functions, the probability of finding one non-reacted monomer molecule can be expressed by $P=X$. If there is no substitution effect, then $P$ is equal to the probability of finding both one non-reacted $\mathrm{OH}-2\left(p_{2}\right)$ and one non-reacted $\mathrm{OH}-5\left(p_{5}\right)$ groups at a time $\mathrm{t}$ and can be expressed as:

$$
\begin{gathered}
P=p_{2} \bullet p_{5}=x_{2 t} \bullet x_{5 t} \text { with } x_{i t}=\frac{[\mathrm{OH}-\mathrm{i}]_{t}}{[\mathrm{OH}-\mathrm{i}]_{0}} \\
x_{t}=\frac{[\mathrm{OH}]_{t}}{[\mathrm{OH}]_{0}}=\frac{[\mathrm{OH}-2]_{t}+[\mathrm{OH}-5]_{t}}{[\mathrm{OH}-2]_{0}+[\mathrm{OH}-5]_{0}}=\frac{1}{2}\left(x_{2 t}+x_{5 t}\right)
\end{gathered}
$$

If $\mathrm{OH}-2$ and $\mathrm{OH}-5$ are equireactive, then $P$ is more simply equal to the probability of finding two nonreacted hydroxyl functions at a time $t$, thus to the squared probability of finding one non-reacted hydroxyl function $(p)$ :

$$
P=p^{2}=x_{t}^{2} \quad \text { with } x_{t}=\frac{[\mathrm{OH}]_{t}}{[\mathrm{OH}]_{0}} \text { and thus } x_{t}=\sqrt{X_{t}}
$$


As $[\mathrm{NCO}]_{0} /[\mathrm{OH}]_{0}=1$, and if we suppose that only the reactions depicted in Scheme 1 are involved, then at any time $[\mathrm{OH}]_{t}=[N \mathrm{NOO}]_{t}$ and $A_{t}=x_{t}$. Fig. 4 compares the decrease in $A_{t}$ and $\sqrt{X_{t}}$ with increasing reaction time; the curves are very close to each other, which suggests that in these particular conditions (THF solution, with organotin catalyst) both hydroxyl functions of DAS are actually equireactive.

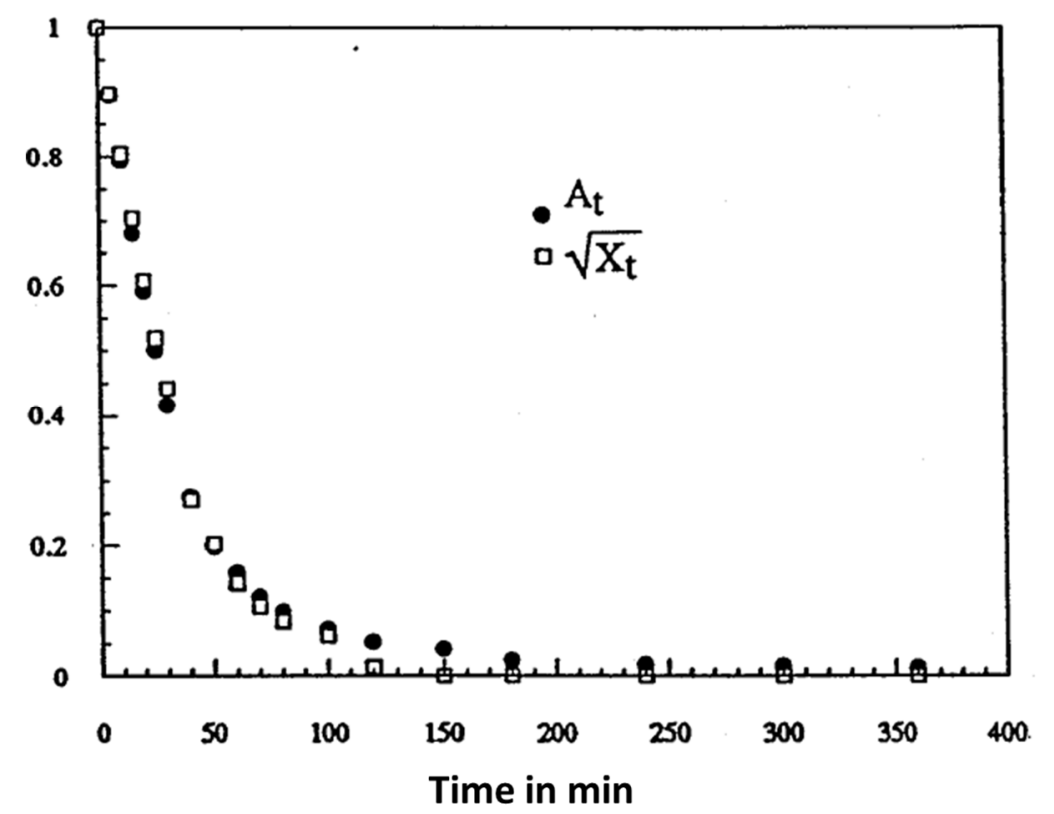

Fig. 4. Comparison between the amount of remaining isocyanate $(\Theta) A_{t}=\frac{[p-\mathrm{TI}]_{t}}{[p-\mathrm{TI}]_{0}}$ and $(\square) \sqrt{X_{t}}\left(X_{t}=\right.$ $\left.\frac{[D A S]_{t}}{[D A S]_{0}}\right) ;\left(\right.$ THF solution, temp. $=50^{\circ} \mathrm{C}$, catalyst $=$ SnDBDL $)$

The unexpected equireactivity of the two hydroxyl groups of DAS can be confirmed by ${ }^{1} \mathrm{H}$ NMR spectroscopy. Indeed, this method allows to distinguish DAS, MonoU2, MonoU5 and DiU. Using adequate conditions, an evaluation of the NMR spectrum of a representative reacting mixture allows a quantitative determination of the formed products.

Assuming that DAS $(1 \mathrm{~mol})$ is reacted with $\mathrm{p}-\mathrm{Tl}(r \mathrm{~mol})$, the probability of finding a DAS molecule is still given by:

$$
P_{\mathrm{DAS}}=p_{2} \cdot p_{5}=x_{2 t} \cdot x_{5 t}=\frac{[\mathrm{OH}-2]_{t}}{[\mathrm{OH}-2]_{0}} \cdot \frac{[\mathrm{OH}-5]_{t}}{[\mathrm{OH}-5]_{0}}
$$

The probability of finding a MonoU2 molecule is the probability of finding both a non-reacted $\mathrm{OH}-5$ group $\left(p_{5}\right)$ and a reacted $\mathrm{OH}-2$ group $\left(1-p_{2}\right)$ :

$$
P_{\text {MonoU2 }}=p_{5} \cdot\left(1-p_{2}\right)=\frac{[\mathrm{OH}-5]_{t}}{[\mathrm{OH}-5]_{0}} \cdot\left(1-\frac{[\mathrm{OH}-2]_{t}}{[\mathrm{OH}-2]_{0}}\right)
$$

and likewise

$$
P_{\text {Monou } 5}=p_{2} \cdot\left(1-p_{5}\right)=\frac{[\mathrm{OH}-2]_{t}}{[\mathrm{OH}-2]_{0}} \cdot\left(1-\frac{[\mathrm{OH}-5]_{t}}{[\mathrm{OH}-5]_{0}}\right)
$$

Finally the probability of finding a DiU molecule can be written as: 


$$
P_{\mathrm{DiU}}=\left(1-\frac{[\mathrm{OH}-2]_{t}}{[\mathrm{OH}-2]_{0}}\right) \cdot\left(1-\frac{[\mathrm{OH}-5]_{t}}{[\mathrm{OH}-5]_{0}}\right)
$$

In the case of equireactive $\mathrm{OH}-2$ and $\mathrm{OH}-5$ groups, $[\mathrm{OH}-2]_{t}$ remains equal to $[\mathrm{OH}-5]_{t}$ all the time. Moreover, $[\mathrm{OH}-2]_{t}=[\mathrm{OH}-2]_{0} \bullet\left(1-\frac{r}{2}\right)$, and consequently for equireactive $\mathrm{OH}$ groups:

$$
\begin{gathered}
P_{\mathrm{DAS}}=\left(1-\frac{r}{2}\right)^{2} \\
P_{\text {MonoU2 }}=P_{\text {MonoU5 }}=\frac{r}{2} \cdot\left(1-\frac{r}{2}\right) \\
P_{\text {DiU }}=\left(\frac{r}{2}\right)^{2}=\frac{r^{2}}{4}
\end{gathered}
$$

In our case $r=1$, hence $P_{\mathrm{DAS}}=P_{\text {MonoU2 }}=P_{\text {Monous }}=P_{\mathrm{DiU}}=0.25$. Equal amounts of DAS, MonoU2, MonoU5 and DiU should thus be found by ${ }^{1} \mathrm{H}$ NMR spectroscopy if both $\mathrm{OH}$ groups are actually equireactive.

Fig. 5 depicts the useful part of the ${ }^{1} \mathrm{H}$ NMR spectrum of the product of the reaction of 1 mole of DAS with 1 mole of $p$-TI.

As the signals associated with $\mathrm{H}_{3}$ and $\mathrm{H}_{4}$ are well separated from the others, they were used for quantitative analysis. The $\mathrm{H}_{3}$ and $\mathrm{H}_{4}$ of DAS and DiU could be assigned without ambiguity with the help of DAS and diurethane spectra. As it can be seen in the spectra, substitution shifts the peaks downfield. The respective assignments of $\mathrm{H}_{3}$ and $\mathrm{H}_{4}$ were inferred from the fact that $\mathrm{H}_{3}$ must be represented by a doublet and $\mathrm{H}_{4}$ by a triplet. In addition, considering the substitution effects, $\mathrm{H}_{4}$ (MonoU5) must be more deshielded than $\mathrm{H}_{4}$ (MonoU2) whereas $\mathrm{H}_{3}$ (MonoU5) must be less deshielded than $\mathrm{H}_{3}$ (MonoU2).

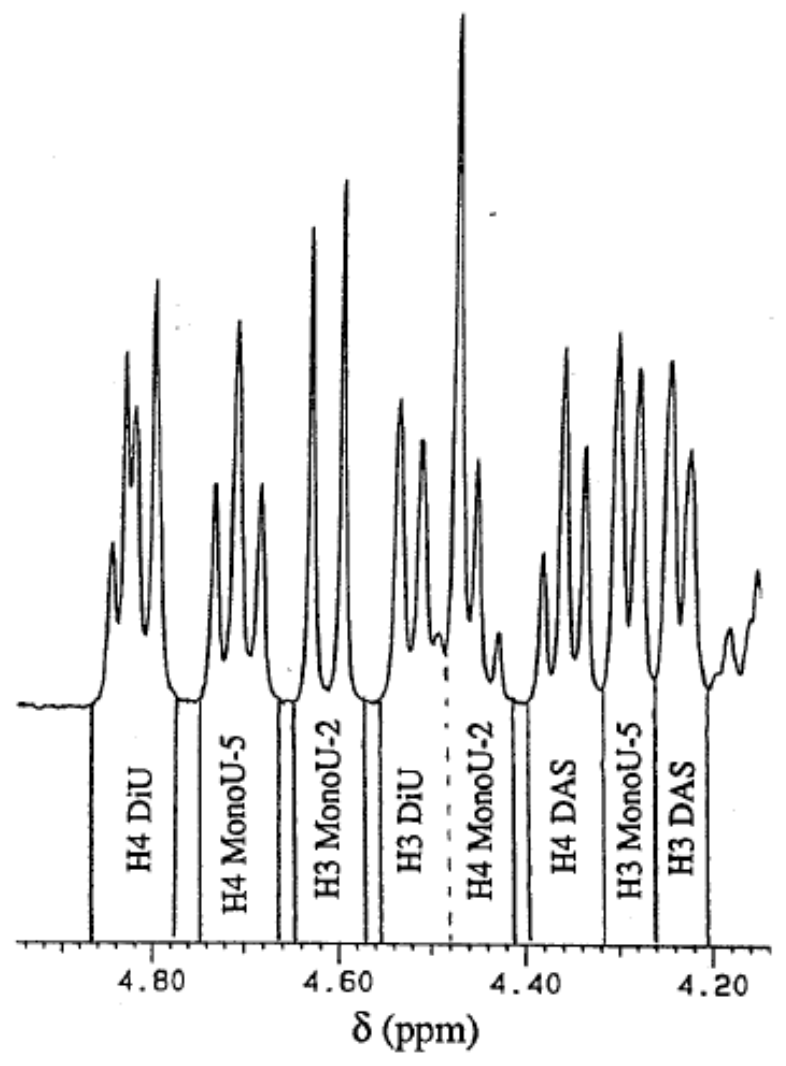

Fig. 5. ${ }^{1} \mathrm{H}$ NMR spectrum (DMSO- $d_{6}, 200 \mathrm{MHz}$ ), of the reacting mixture DAS (1 mole)/p-TI (1 mole) 
Tab. 1. ${ }^{1} \mathrm{H}$ NMR analysis of the reaction between DAS and $p-\mathrm{TI}(r=1)$ in catalyzed THF solution $\left(50^{\circ} \mathrm{C}\right)$; chemical shifts, assignments and integration of the peaks associated with protons $\mathrm{H}_{3}$ and $\mathrm{H}_{4}$

\begin{tabular}{|l|l|l|}
\hline Chemical shifts $\delta$ in ppm & Assignments & Integration \\
\hline 4.82 & $\mathrm{H}_{4}$ DiU & 7.6 \\
$4.52-4.44$ & $\mathrm{H}_{3}$ DiU + $\mathrm{H}_{4}$ MonoU2 & 11.1 \\
4.61 & $\mathrm{H}_{3}$ MonoU2 & 4.8 \\
4.70 & $\mathrm{H}_{4}$ MonoU5 & 5.75 \\
4.29 & $\mathrm{H}_{3}$ MonoU5 & 5.5 \\
4.36 & $\mathrm{H}_{4}$ DAS & 4.95 \\
4.23 & $\mathrm{H}_{3}$ DAS & 5.2 \\
\hline
\end{tabular}

The signals given by the four products were rather well separated and thus the areas of the various peaks could be compared in Tab. 1.

Although the triplet given by $\mathrm{H}_{4}$ (DiU) is not well defined, the other peak areas are quite similar; therefore, this NMR analysis leads to the same conclusion as SEC, i.e. that under our conditions (THF solution; catalyst: $\mathrm{SnDBDL} ; 50^{\circ} \mathrm{C}$ ), the hydroxyl groups of DAS are definitely equireactive.

According to the different steric and electronic considerations stated above, this result is rather unexpected. Numerous works regarding DAS esterification actually mention different reactivities for the two hydroxyl groups ${ }^{10,12-17)}$. Depending on the reaction conditions, an inversion of the order of reactivity can even be observed. One can thus imagine that appropriate experimental conditions could allow to equilibrate both reactivities: the intramolecular hydrogen bond would activate the $\mathrm{OH}-5$ by increasing the nucleophilicity of its oxygen atom; on the contrary, the $\mathrm{Bu}_{2} \mathrm{Sn}^{2+}$ ion, which usually catalyzes the reaction between $\mathrm{OH}$ and $\mathrm{NCO}$ functions via the formation of a mixt complex, would be almost totally hindered when linked to the $\mathrm{OH}-5$, because of the two oxygen atoms in the vicinity. As shown in Fig. 6, the coordination of the isocyanate function would not be possible in this case, and thus the organotin catalyst would mostly favor the reaction between $\mathrm{OH}-2$ and NCO functions.

In the literature, steric effects in the ternary complexes alcohol-metal-isocyanate have already been proved to induce differences in the catalyst efficiency, due to the geometry of the complex or to the position of the hydroxyl groups ${ }^{18,19)}$. 


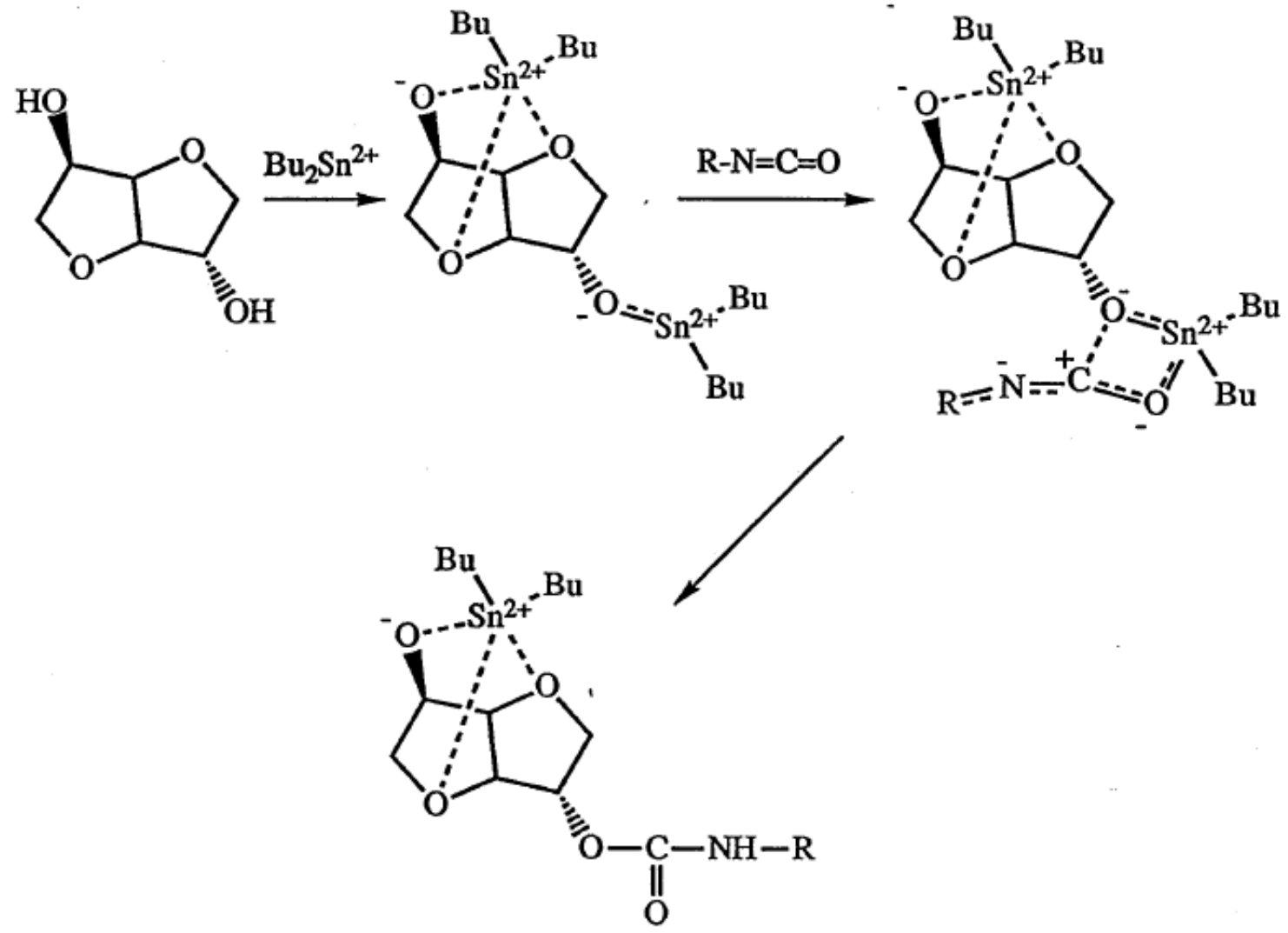

Fig. 6. Possible structure of the $\mathrm{DAS}-\mathrm{Bu}_{2} \mathrm{Sn}^{2+}$-isocyanate complex

\section{Kinetic investigation of the polyurethane synthesis}

Since isosorbide displays equireactive hydroxyl groups in our experimental conditions (THF solution, SnDBDL catalysis), the kinetic study of the reaction between DAS and 4,4'-diphenylmethane diisocyanate (MDI) becomes easier. For these studies, a $1 / 1[\mathrm{NCO}] /[\mathrm{OH}]$ ratio was used.

Fig. 7 shows the evolution of the SEC chromatograms with time. The presence of a small peak at a lower elution time indicates that part of the monomers had already reacted at our conventional starting time. Thanks to a standard straight line, we estimated that at this time $8.8 \%$ monomer had reacted.

The disappearance of the monomers is depicted in Fig. 8. Both reactants are consumed at the same rate.

Numerous works mention a substitution effect for $\mathrm{MDI}^{20 a, b)}$. The isocyanate groups are sensitive to steric hindrance; and once the first isocyanate function has reacted, the second one is reported to be twice to more than three times less reactive, depending on the alcohol, the catalyst and the temperature. 


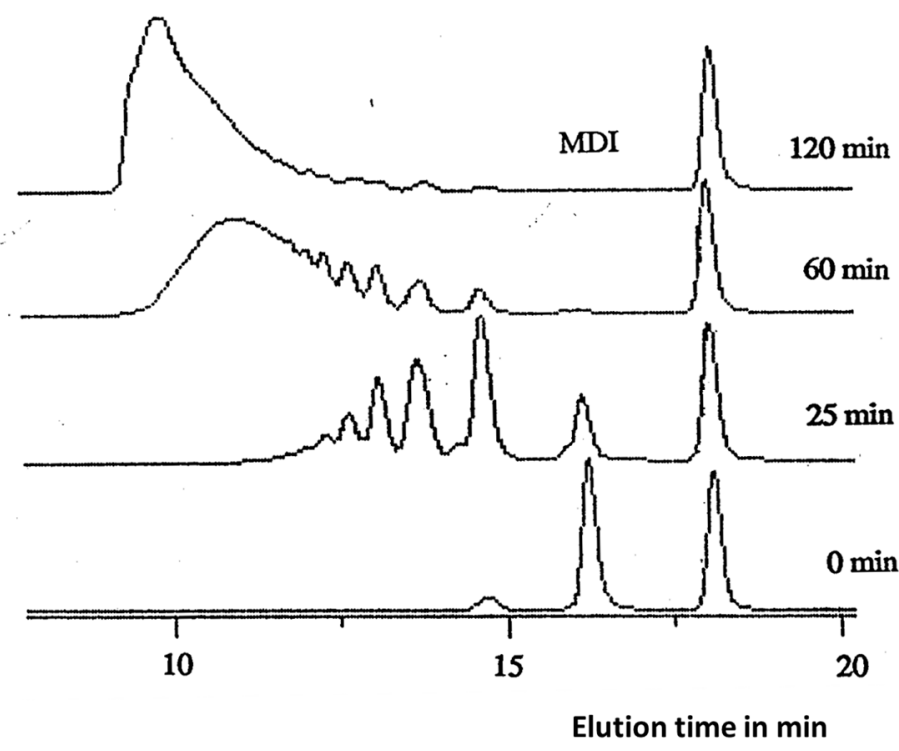

Fig. 7. Evolution of the SEC chromatograms with time during the polycondensation of DAS with MDI (THF solution, temp. $=50^{\circ} \mathrm{C}$, catalyst $=$ SnDBDL) (UV detection, $\lambda=254 \mathrm{~nm}$ )

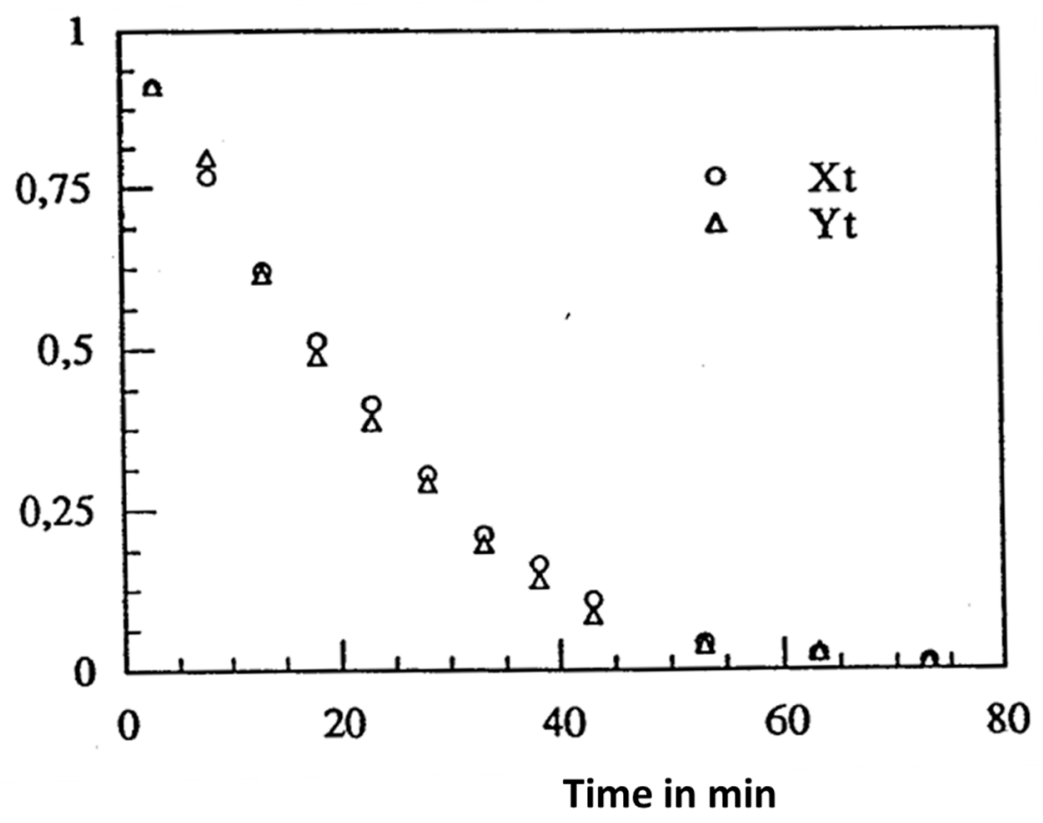

Fig. 8. Decrease in the amount of remaining monomers during the polycondensation of DAS with MDI (THF solution, temp. $=50^{\circ} \mathrm{C}$, catalyst $\left.=\operatorname{SnDBDL}\right) ;(O) X_{t}=\frac{[\mathrm{DAS}]_{t}}{[\mathrm{DAS}]_{0}}$ and $(\triangle) Y_{t}=\frac{[\mathrm{MDI}]_{t}}{[\mathrm{MDI}]_{0}}$

The elementary model for the alcohol-isocyanate reaction in the presence of a catalyst was described by Baker ${ }^{21)}$ as a second-order reaction:

$$
\begin{aligned}
-\frac{\mathrm{d}[\mathrm{NCO}]}{\mathrm{d} t}=-\frac{\mathrm{d}[\mathrm{OH}]}{\mathrm{d} t} & =k_{0} \cdot[\mathrm{NCO}] \cdot[\mathrm{OH}]+k_{\mathrm{c}} \bullet[\mathrm{cat}] \cdot[\mathrm{NCO}] \bullet[\mathrm{OH}] \\
& =\mathrm{k} \cdot[\mathrm{NCO}] \bullet[\mathrm{OH}]
\end{aligned}
$$


where $k=k_{0}+k_{\mathrm{c}} \bullet$ [cat]. Since in our case at any time $[\mathrm{OH}]_{t}=[\mathrm{NCO}]_{t}$, the second order rate constant $k$ can easily be estimated by plotting $1 /\left(1-\alpha_{t}\right)=1 / x_{t}$ as a function of $t$ :

$\frac{1}{1-\alpha_{t}}=\frac{1}{x_{t}}=\mathrm{k} \cdot[\mathrm{OH}]_{0} \cdot \mathrm{t}+1$

( $\alpha_{t}$ is the urethane conversion)

Fig. 9 shows the second-order plot for the reaction between $p$-TI and DAS; the corresponding curve associated with the MDI/DAS system is totally similar. The reaction between DAS and $p$-TI follows second-order kinetics up to $x=58 \%$, and that of DAS with MDI up to $x=70 \%$. Then, the experimental curves exhibit a positive deviation with respect to the second-order straight lines.

Many reactions obey second order kinetics up to a high conversion where a positive or negative incurvation of the experimental data with respect to the theoretical straight line occurs. According to Ephraim ${ }^{22)}$, the formation of a complex between alcohol and solvent would be responsible for this phenomenon. For example, it is well known that there are most of time interaction $s$ between ethers and alcohols (here between THF and DAS).

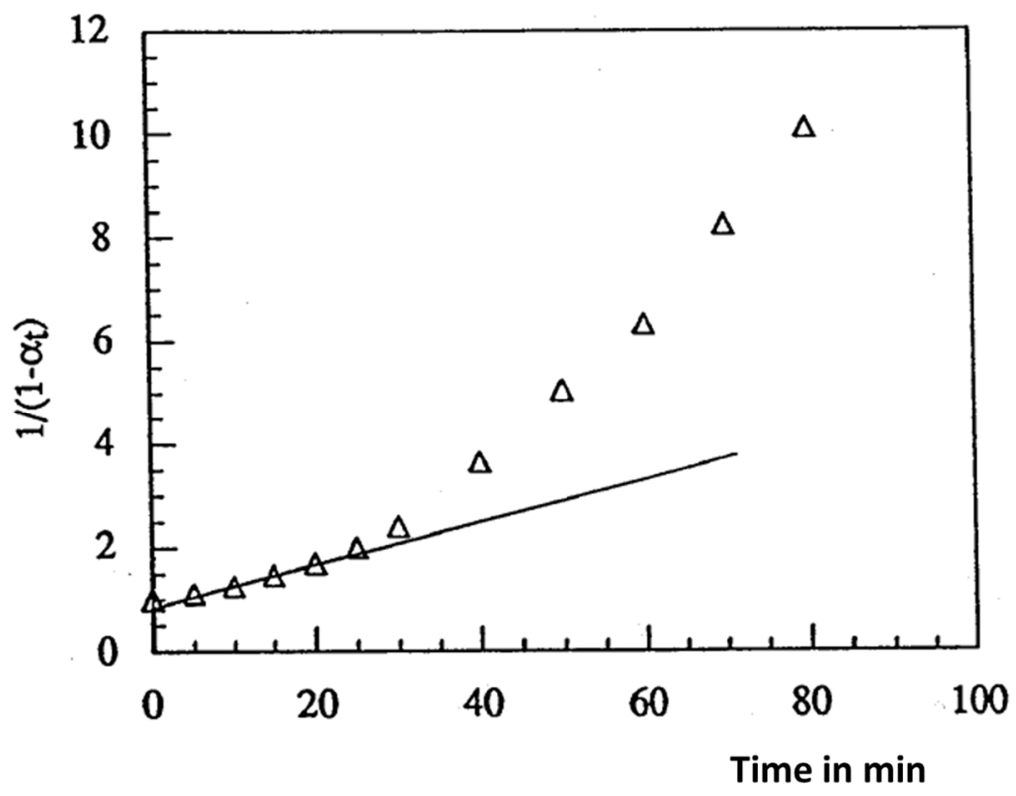

Fig. 9. Application of a second-order kinetic model to the reaction of DAS with p-TI (THF solution, temp. $=50^{\circ} \mathrm{C}$, catalyst $\left.=\mathrm{SnDBDL}\right) ; \alpha_{t}=$ urethane conversion

However, in order to account more precisely for these deviations, the reaction between alcohols and isocyanates was also studied by Sato ${ }^{23)}$, who suggested the following kinetic equation:

$-\frac{d[\mathrm{NCO}]}{d t}=k_{1} \bullet[\mathrm{NCO}] \bullet[\mathrm{OH}] 2+k_{2} \bullet[\mathrm{U}] \bullet[\mathrm{NCO}] \bullet[\mathrm{OH}]+k_{3} \bullet[\mathrm{cat}] \bullet[\mathrm{NCO}] \bullet[\mathrm{OH}]$

where [U] stands for the concentration of formed urethane and $k_{1}, k_{2}$ and $k_{3}$ are the rate constants for the condensation catalyzed by alcohol functions, urethane functions and the catalyst, respectively. In this model, the effects of $\mathrm{OH}$ and urethane groups are consequently not neglected any longer. 
Eq. 2 can be written in the form:

$$
\frac{d \alpha}{d t}=K_{1} \bullet(1-\alpha)^{2}+K_{2} \bullet \alpha(1-\alpha)^{2}
$$

with $K_{1}=k_{1} \bullet A_{0}^{2}+k_{3} \bullet[\mathrm{cat}] \bullet A_{0}$ and $K_{2}=\left(k_{2}-k_{1}\right) A_{0}^{2} \quad\left(A_{0}=[\mathrm{OH}]_{0}=[\mathrm{NCO}]_{0}\right)$

$K_{1}$ and $K_{2}$ can be calculated using Runge-Kutta's method. The results obtained using Eqs. 1 and 3 are expressed in Tab. 2.

Tab. 2. Rate constants for second-order ( $k$, Eq. 1$)$ and third-order kinetics ( $K_{1}$ and $K_{2}$, Eq. 3 ) for the reaction between isosorbide and $p$-tolyl isocyanate or 4,4'-diphenylmethane diisocyanate

\begin{tabular}{|c|c|c|c|}
\hline Reactive system & $\boldsymbol{k} / \mathrm{min}^{-1}$ (Eq. 1) & $\boldsymbol{K}_{1} / \mathrm{min}^{-1}$ (Eq. 3) & $\boldsymbol{K}_{2} / \mathbf{m i n}^{-\mathbf{1}}$ (Eq. 3) \\
\hline $\mathrm{DAS} / p-\mathrm{TI}$ & $4.16 \cdot 10^{-2}$ & $1.12 \cdot 10^{-2}$ & $13.53 \cdot 10^{-2}$ \\
$\mathrm{DAS} / \mathrm{MDI}$ & $1.96 \cdot 10^{-2}$ & $0.28 \cdot 10^{-2}$ & $13.99 \cdot 10^{-2}$ \\
\hline
\end{tabular}

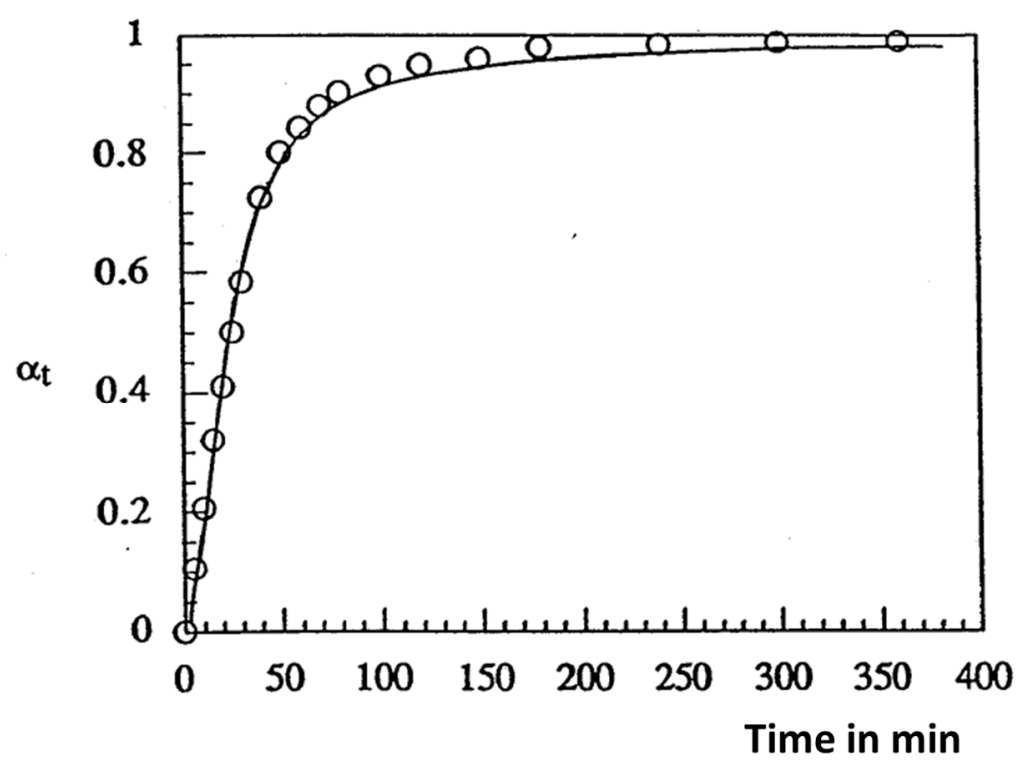

Fig. 10. Simulated (using Sato's equation) (-) and experimental (O) urethane conversion $a_{t}$ versus time curves for the reaction of DAS with $p-\mathrm{TI}$ (THF solution, temp. $=50^{\circ} \mathrm{C}$, catalyst $=\mathrm{SnDBDL}$ ) 


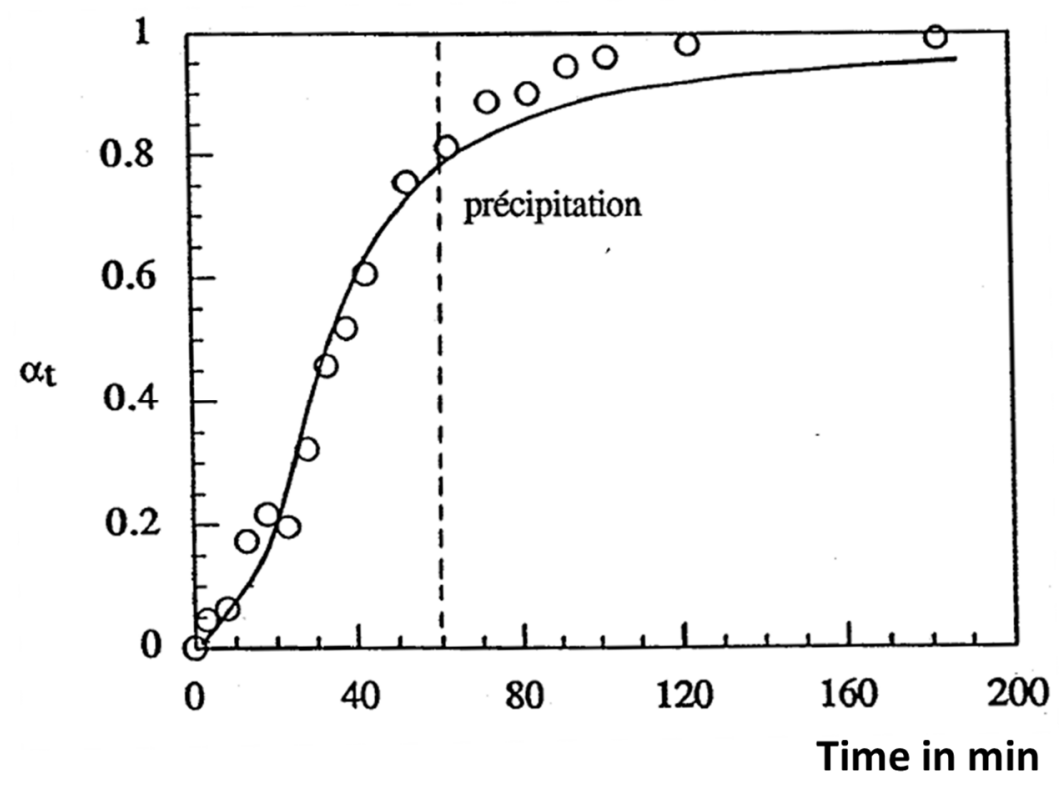

Fig. 11. Simulated (using Sato's equation) $(-)$ and experimental $(O)$ urethane conversion $a_{t}$ versus time curves for the reaction of DAS with MDI (THF solution, temp. $=50^{\circ} \mathrm{C}$, catalyst $=\mathrm{SnDBDL}$ )

Fig. 10 shows the experimental and simulated (using Sato's equation) curves for the reaction between DAS and $\mathrm{pTI}$. A reasonable fit of the reaction profile could be achieved with the model. It was established above that this system follows second-order kinetics and then shows a positive deviation, and therefore we can postulate that this deviation is due to the catalytic effect of the formed urethane since the hydroxyl concentration decreases with increasing time.

The corresponding experimental and calculated curves for the reaction of DAS with MDI are shown in Fig. 11. The model fits the experimental curve only up to $t=60 \mathrm{~min}$; afterwards a positive deviation is once again observed. This time happens to be the moment when precipitation of the DAS/MDI polymer in the reactive medium was first observed. It has been demonstrated in the literature that precipitation affects the rate of reactions since it controls the rate of mass transfer of the reactants. Pearson ${ }^{24)}$ showed that the heterogeneous rate constants in interfacial isocyanate/alcohol polycondensations were higher than those obtained for the homogeneous conditions, although the mechanism was apparently the same; he suggested that the reactant molecules could in some way be more favorably presented at the reaction interface under heterogeneous conditions.

\section{Characterization of polyurethane hard segments based on DAS}

- Chemical structure

Fig. 12 shows the ${ }^{1} \mathrm{H}$ NMR spectrum of the polyurethane obtained in solution and recovered by precipitation in methanol. The various chemical shifts and their corresponding assignments are reported in Tab. 3. Due to the dissymmetrical structure of 1,4:3,6-dianhydro-2,5 D-sorbitol units, the spectrum is rather complicated. The different chemical shifts have nevertheless all been attributed with the help of previous works about DAS ${ }^{1,11,12)}$. The anisotropy of the carbonyl oxy groups induces a 
change in the chemical shifts of the protons of DAS once it has been substituted. Small peaks in the $\mathrm{H}_{3}-\mathrm{H}_{4}$ region (indicated by asterisks) can be associated with DAS chain ends.

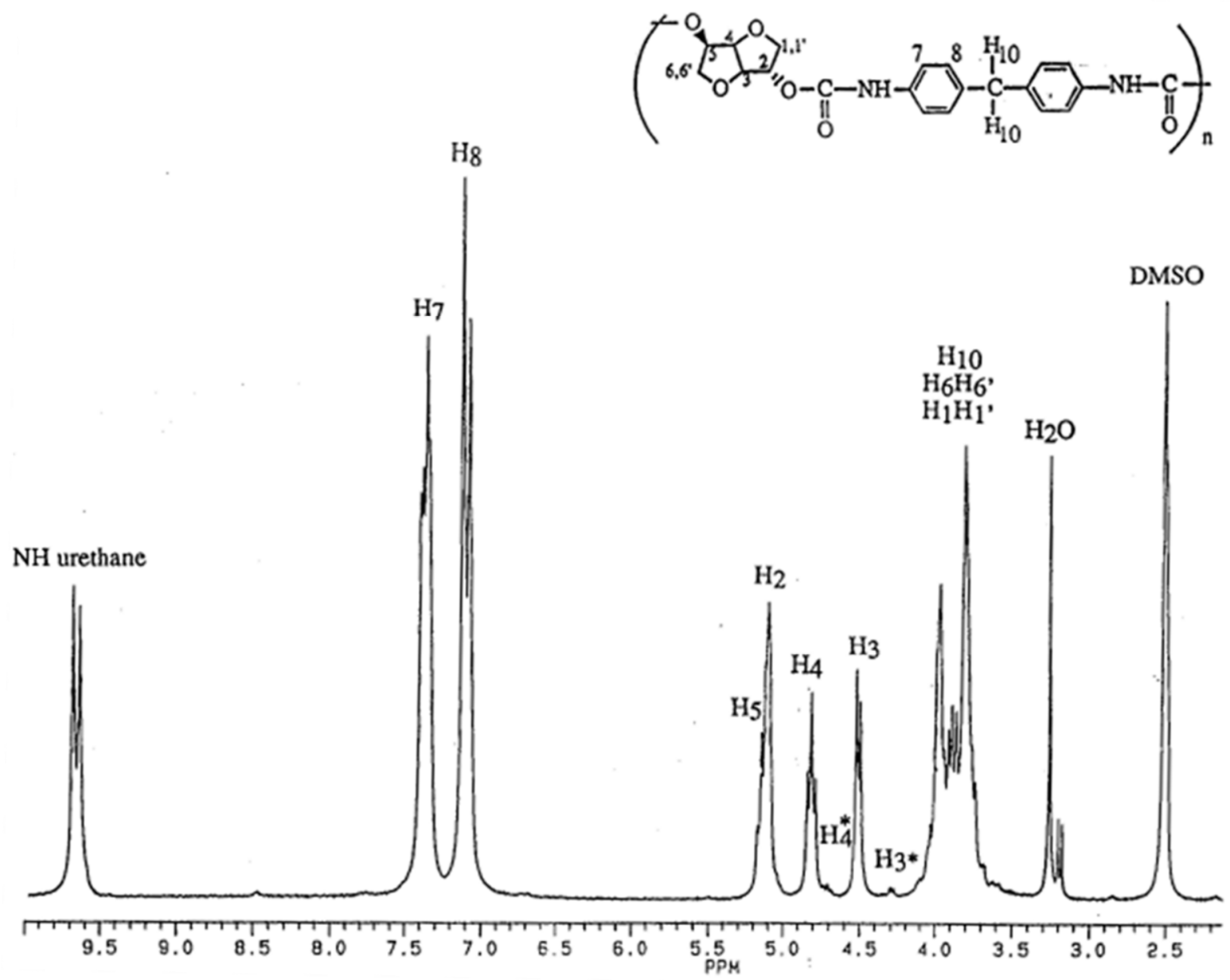

Fig. 12. ${ }^{1} \mathrm{H}$ NMR spectrum (DMSO- $d_{6}, 200 \mathrm{MHz}$ ) of the hard segment based on DAS and MDI $\left([\mathrm{NCO}]_{0} /[\mathrm{OH}]_{0}=1\right.$, solution polycondensation)

- Molecular weight analysis

The polyurethane based on MDI and isosorbide is essentially not soluble in THF, a common solvent and eluent for SEC analysis. However, a chemical modification by trifluoroacetic anhydride can be used to improve its solubility. This technique was often applied to semi-crystalline polymers such as polyamides ${ }^{25,26)}$ and more recently to polyurethanes ${ }^{27)}$. Jacobi et al. ${ }^{25)}$ reported that the reaction was quantitative and reproducible for polyamides, whereas we have shown ${ }^{27,28)}$ that it was only partial for polyurethanes. 
Tab. 3. ${ }^{1} \mathrm{H}$ NMR chemical shifts and their respective assignments for the (MDI-DAS) ${ }_{n}$ polyurethane synthesized in solution

\begin{tabular}{|l|l|}
\hline Chemical shifts $\delta$ in ppm & Assignment \\
\hline 2.50 & $\mathrm{DMSO}$ \\
3.20 & $\mathrm{H}_{2} \mathrm{O}$ \\
$3.80-4.00$ & $\mathrm{H}_{1}, \mathrm{H}^{\prime}, \mathrm{H}_{6}, \mathrm{H}_{6}{ }_{6}$ and $\mathrm{H}_{10}$ \\
4.28 & $\mathrm{H}_{3}{ }^{*}$ (chain ends) \\
4.70 & $\mathrm{H}_{4}{ }^{*}$ (chain ends) \\
4.80 & $\mathrm{H}_{4}$ \\
5.10 & $\mathrm{H}_{2}, \mathrm{H}_{5}$ \\
7.11 & $\mathrm{H}_{8}, \mathrm{H}_{8}{ }_{8}$ \\
7.37 & $\mathrm{H}_{7}, \mathrm{H}^{\prime}{ }_{7}$ \\
9.68 & $\mathrm{NH}$ (urethane) \\
\hline
\end{tabular}

The modification was run in a $1 \%$ polyurethane solution or suspension in THF, with excess trifluoroacetic anhydride. In the case of polyurethanes, it can be written as:

Scheme 2: Modification of urethane functions with trifluoroacetic anhydride

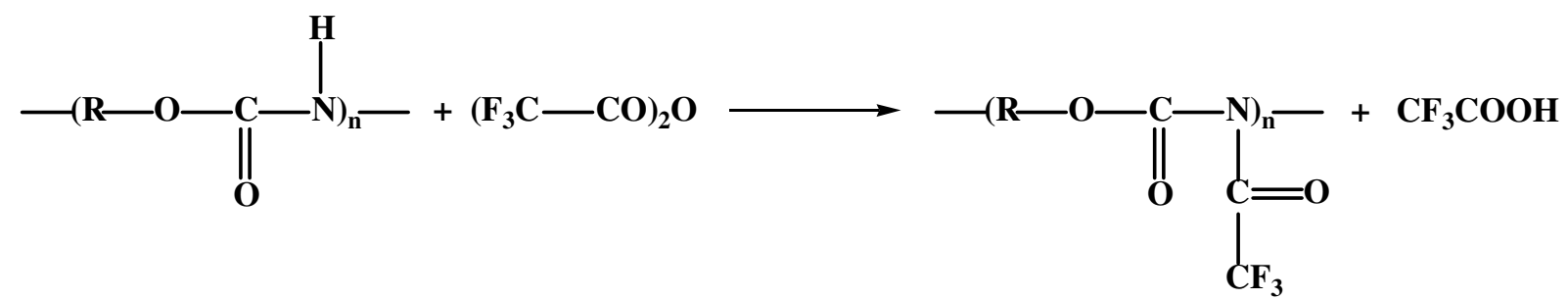

According to Darud ${ }^{27}$, the kinetics and the reaction yield depend on the chemical structure of the polyurethane and on the nature of the solvent. Here the resulting $\mathrm{N}$-trifluoroacetylated polymer is totally soluble in THF. Moreover, this chemical modification was proved to systematically induce a decrease in the apparent molecular weights determined by SEC measurements, as compared to that of the corresponding soluble fractions.

Tab. 4 shows the number- $\left(\overline{M_{n}}\right)$ and weight- $\left(\overline{M_{w}}\right)$ average molecular weights obtained for the polyurethanes obtained by bulk (modified polymer) and solution polycondensation.

The higher polydispersity index obtained in solution is probably due to the precipitation during the reaction. Apart from this, no striking difference appears between the two kinds of experimental procedure.

Tab. 4. Number- and weight average molecular weights of (MDI-DAS) $n$ polyurethanes as determined by SEC analysis (polystyrene standards)

\begin{tabular}{|l|l|l|l|}
\hline $\begin{array}{l}\text { Experimental } \\
\text { conditions }\end{array}$ & \multicolumn{1}{|c|}{$\overline{M_{n}}$} & $\overline{M_{w}}$ & $I_{\mathrm{p}}{ }^{\text {a) }}$ \\
\hline bulk & 13000 & 31000 & 2.4 \\
solution & 15000 & 41000 & 2.7 \\
\hline
\end{tabular}

a) Molecular weight distribution. 
- Thermal properties

The DSC curves obtained with the (MDI-DAS) ${ }_{n}$ hard segment are represented in Fig. 13 . According to the synthesis procedure, the morphology is totally different.

\section{Bulk polycondensation}

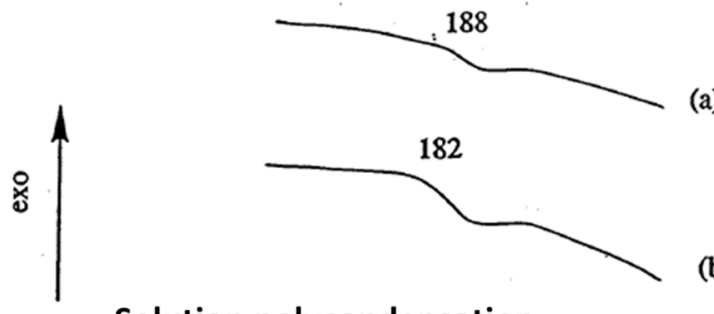

Solution polycondensation

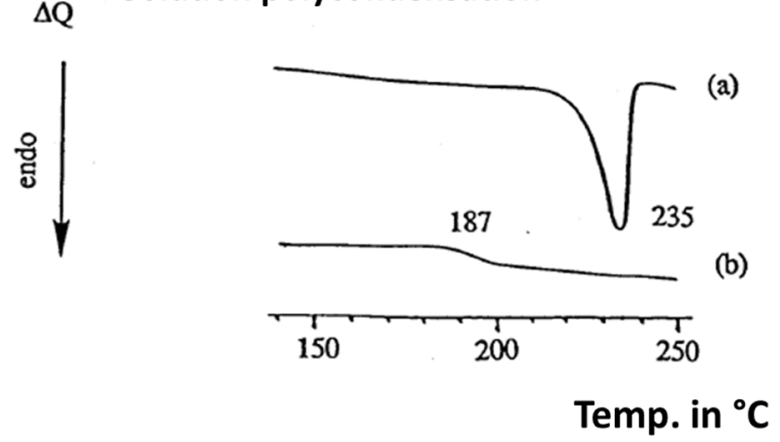

Fig. 13. DSC curves: first scan (a) and second scan (after a quench) (b) of the (DAS-MDI) hard segment prepared in bulk or in THF solution

The polyurethane prepared in solution is highly crystalline at the beginning. It presents a melting endotherm at $235^{\circ} \mathrm{C}$ on the first DSC curve. However, recrystallization is not observed; the polymer looks amorphous in the second scan. This may result from the proximity of the glass transition $\left(187^{\circ} \mathrm{C}\right)$ and melting temperatures. Similar behaviors were observed by Fu et al. ${ }^{29)}$ on polyurethanes based on 2,4-toluene diisocyanate and 1,4-butanediol; a quench from above glass transition to low temperature at a rate of $10 \mathrm{~K} / \mathrm{min}$ is sufficient to prevent the polyurethane from crystallizing.

On the contrary, the polyurethane prepared in bulk appears entirely amorphous, even at the first scan. This suggests that as it is commonly observed, crystallization probably occurs during the precipitation of the polymer synthesized in solution, but that it is difficult to obtain crystallization for the bulk sample after a long thermal treatment at $200^{\circ} \mathrm{C}$. Quite surprisingly, the $T_{\mathrm{g}}$ of the bulk sample decreases from 188 to $182^{\circ} \mathrm{C}$ after the first DSC scan. This would indicate some degradation or at least rearrangement of the polymer chains. Such phenomena were observed in the literature for this particular polymer starting from about $230^{\circ} \mathrm{C}$, with a maximum degradation rate at $340^{\circ} \mathrm{C}^{7}$ (but in this case the sample, prepared by solution polycondensation in dimethyl sulfoxide, had a much lower glass transition temperature, $T_{\mathrm{g}}=102^{\circ} \mathrm{C}$. This latter value is rather surprising since the molecular weights of the sample seem to be close to ours).

In our case, the $T_{\mathrm{g}}$ of this MDI-DAS polymer is remarkably high, probably due to the rigid structure of DAS: it can be compared to the much lower value found for a similar hard segment based on MDI and a softer diol of the same length such as 1,4-butanediol $\left(T_{\mathrm{g}}=107^{\circ} \mathrm{C}^{28)}\right.$, see below). A comparison between rigid polyurethanes obtained with DAS and with various common diols ${ }^{28)}$ is given in Tab. 5 . 
Tab. 5. Comparison of the polyurethane hard segment based on MDI and isosorbide with other common hard segments based on commercial diols (from ref. ${ }^{28}$ ). All polymers were synthesized in solution

\begin{tabular}{|c|c|c|c|c|c|c|}
\hline $\begin{array}{l}\text { Chemical } \\
\text { structure }\end{array}$ & $\overline{M_{n}}$ & $\overline{M_{w}}$ & $I_{\mathrm{p}}$ & $\mathrm{T}_{\mathrm{g}} /{ }^{\circ} \mathrm{C}$ & $\Delta C_{\mathrm{p}} /\left(\mathrm{J} \cdot \mathrm{g}^{-1} \cdot \mathrm{K}^{-1}\right)$ & $T_{\mathrm{m}} /{ }^{\circ} \mathrm{C}$ \\
\hline$(\mathrm{MDI}-\mathrm{DAS})_{n}$ & $15000^{\text {a) }}$ & $41000^{\text {a) }}$ & 2.7 & $187^{b)}$ & 0.32 & 235 \\
\hline$(\mathrm{MDI}-\mathrm{BDO})_{n}{ }^{\mathrm{c})}$ & $24300^{\text {a) }}$ & $41300^{\text {a) }}$ & 1.7 & $107^{b)}$ & 0.39 & $198-225-240$ \\
\hline$\left.(\mathrm{MDI}-\mathrm{HQEE})_{n} \mathrm{c}\right)$ & insoluble & insoluble & & $98^{b)}$ & 0.40 & $215-245$ \\
\hline$(\mathrm{MDI}-\mathrm{CHDM})_{n}{ }^{\mathrm{c}}$ & 48200 & 91600 & 1.9 & $134^{b)}$ & 0.30 & $190-210$ \\
\hline$(\mathrm{MDI}-\mathrm{NPG})_{n}{ }^{\mathrm{c})}$ & 11600 & 22100 & 1.9 & 94 & 0.34 & amorphous \\
\hline
\end{tabular}

a) Soluble in THF only after chemical modification by trifluoroacetic anhydride.

b) $T_{\mathrm{g}}$ values obtained after two DSC scans, after an initial scan followed by quenching.

c) BDO : 1,4-butanediol; HQEE : $\beta, \beta^{\prime}$-dihydroxyethylhydroquinone; CHDM : 1,4-cis/transdihydroxymethylcyclohexane; NPG : 2,2-dimethyl-1,3-propanediol (neopentyl glycol).

From a general point of view, the glass transition temperature of the polymer obtained with DAS is strikingly above the values associated with all the others. This makes it a particularly interesting candidate for the chain extension of segmented polyurethanes, since the thermal stability of their hard segments would be greatly improved compared to classical systems. Moreover, its melting temperature is not too high $\left(235^{\circ} \mathrm{C}\right)$ and this polymer should thus remain processable at reasonable temperatures.

\section{Synthesis of hard segments of differential lengths}

Several polyurethanes were synthesized using various $\mathrm{NCO} / \mathrm{OH}$ ratios $(7 / 6,5 / 4,3 / 2$ and 1/1). Fig. 14 displays typical SEC chromatograms of the samples, before and after their precipitation in methanol. By this technique, the excess MDI is removed from the polyurethane. The chromatograms show that the hard segments prepared in this way are blends of macromolecules of different length. This result is confirmed by the DSC curves depicted in Fig. 15; the different melting endotherms come from the discontinuous distribution of chain length in the sample. 


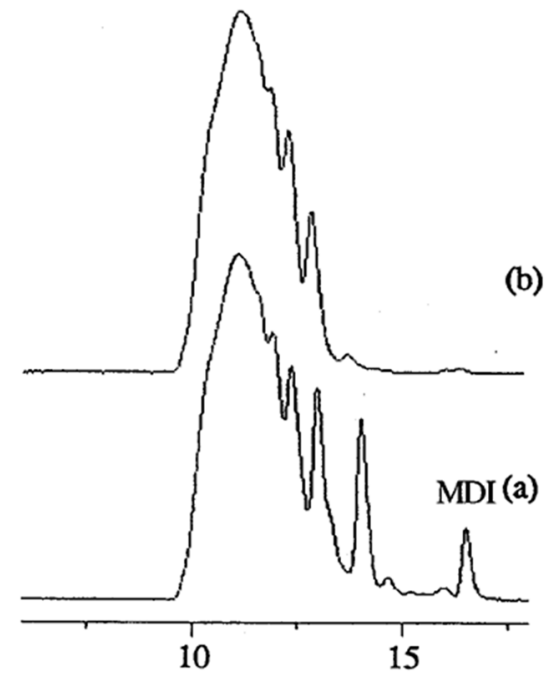

Elution time in $\min$

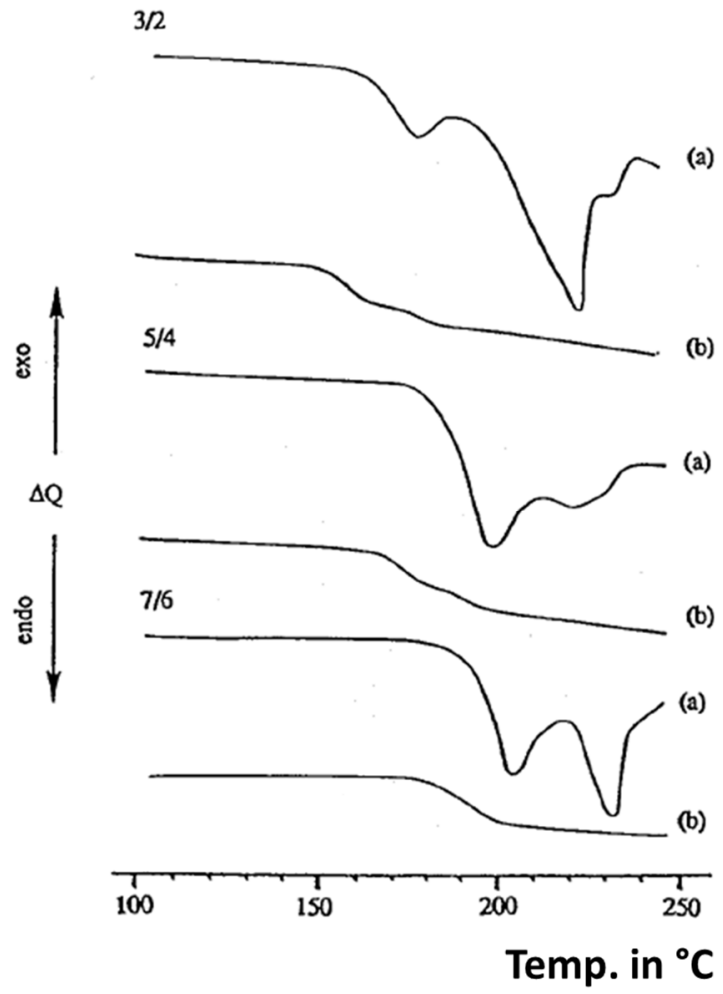

Fig. 14. SEC chromatograms of the crude (a) and precipitated (b) (MDI-DAS) $n$ polyurethane prepared in THF solution $\left([\mathrm{NCO}]_{0} /[\mathrm{OH}]_{0}=3 / 2\right)$ (refractometric detection)
Fig. 15. DSC curves of the MDI-DAS hard segments obtained with various excess amounts of MDI: $[\mathrm{NCO}]_{0} /[\mathrm{OH}]_{0}=3 / 2,5 / 4,7 / 6$; first scan (a) and second scan (after a quench) (b)

All the molecular weights and $T_{\mathrm{g}}$ values of the various samples are gathered in Tab. 6 . 
Tab. 6. Characterization of the hard segments obtained from the polycondensation of DAS with various amounts of MDI

\begin{tabular}{|c|c|c|c|c|}
\hline $\mathbf{N C O} / \mathbf{O H}$ & $\overline{\boldsymbol{M}_{\boldsymbol{n}}}$ & $\overline{\boldsymbol{M}_{\boldsymbol{w}}}$ & $\boldsymbol{I}_{\mathbf{p}}$ & $\boldsymbol{T}_{\mathrm{g}}{ }^{\circ} \mathbf{C}$ \\
\hline $3 / 2$ & 3100 & 4300 & 1.4 & 154 \\
$5 / 4$ & 4800 & 10300 & 2.1 & 170 \\
$7 / 6$ & 7100 & 13500 & 1.9 & 183 \\
$1 / 1$ & 15000 & 41000 & 2.7 & 187 \\
\hline
\end{tabular}

$T_{\mathrm{g}}$ can be plotted versus the inverse of the number-average molecular weight (Fig. 16). A straight line is obtained, which can be described by a relationship analogous to the Fox-Flory relation ${ }^{30)}$ :

$$
T_{g}=T_{g \infty}-\frac{K}{\overline{M_{n}}}
$$

where $T_{\mathrm{g} \infty}$ is the $T_{\mathrm{g}}$ of a hard segment of infinite molecular weight and $K$ is a constant. Here we find experimentally $K=13.1 \cdot 10^{4} \mathrm{~K}$ and $T_{\text {go }}=190^{\circ} \mathrm{C}$. This would mean that our solution synthesis with stoichiometric $\mathrm{NCO} / \mathrm{OH}$ ratio almost allows to reach the maximum $T_{\mathrm{g}}$.

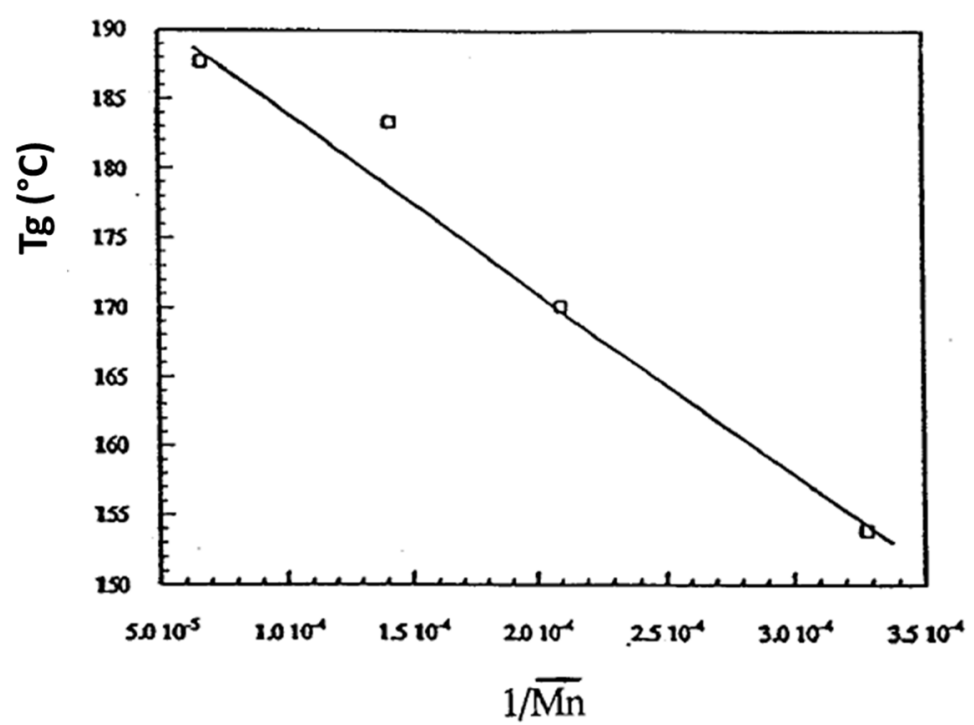

Fig. 16. Fox-Flory plot of $T_{\mathrm{g}}$ versus $1 / \overline{M_{n}}$ for MDI-DAS hard segments of different length

\section{Conclusion}

The equireactivity towards isocyanate functions of the two hydroxyl groups of 1,4:3,6dianhydrosorbitol (DAS) in the presence of a catalyst (dibutyltin dilaurate) was established in a model kinetic study with a monofunctional aromatic isocyanate. The results were then applied to the kinetic study of the polycondensation of DAS with 4,4'-diphenylmethane diisocyanate (MDI). The kinetics can be described by a second order equation, modified to take into account catalysis by the formed urethane functions (Sato's equation). 
The structure of the (MDI-DAS) polymer was fully characterized by ${ }^{1} \mathrm{H}$ NMR spectroscopy. No particular side reaction was found, except a slight hydrolysis of some isocyanate functions which probably occurred during the recovery of the polymer.

When the reactants were used in stoichiometric ratio $(\mathrm{NCO} / \mathrm{OH}=1)$, the average molecular weights of the resulting polyurethane were reasonably high. The value obtained for its $T_{\mathrm{g}}$ was remarkably high: we obtained 187 "C, i.e. very close to the value of $T_{\mathrm{g} \infty}$ that can be deduced from the measurements on oligomers of different length $\left(T_{\mathrm{g} \infty}=190^{\circ} \mathrm{C}\right)$. These results make the (MDI-DAS) hard segment an interesting compound for the preparation of high performance segmented polyurethanes.

The authors express their thanks to Roger Petiaud (CNRS, Service Central d'Analyse, Vernaison) for NMR analyses and to Roquette Frères, Lestrem, France, for supplying 1,4:3,6-dianhydrosorbitol and supporting this work.

1) P. Stoss, R. Hemmer, Adv. Carbohydrate Chem. Biochem. 49, 93 (1991)

2) G. Flèche, M. Huchette, Starch/Stärke 38, 26 (1986)

3) J. Thiem, H. Lüders, Starch/Stärke 36, 170 (1984)

4) J. Thiem, H. Lüders, Polym. Bull. (Berlin) 11, 365 (1984)

5) J. Thiem, Makromol. Chem. 187, 2775 (1986)

6) R. Storbeck, M. Rehahn, M. Ballauff, Makromol. Chem. 194, 53 (1993)

7) D. Braun, M. Bergmann, J. Prakt. Chem. 334, 298 (1992)

8) J. Thiem, F. Bachmann, Makromol. Chem. 192, 2163 (1991)

9) F. Jacquet, R. Audinos, M. Delmas, A. Gaset, Biomass 6, 193 (1985)

10) A. C. Cope, T. Y. Shen, J. Am. Chem. Soc. 78, 3177 (1956)

11) F. J. Hopton, G. H. S. Thomas, Can. J. Chem. 47, 2395 (1969)

12) J. A. Peters, W. M. M. J. Bovee, A. P. G. Kieboom, Tetrahedron 40 (15), 2885 (1984)

13) R. U. Lemieux, A. G. McInnes, Can. J. Chem. 38, 136 (1960)

${ }^{14)}$ K. W. Buck, J. M. Duxbury, A. B. Foster, A. R. Perry, J. M. Webber, Carbohydrate Res. 2, 122 (1966)

15) J. C. Goodwin, J. E Hodge, D. Weisleder, Carbohydrate Res. 79, 133 (1980)

16) G. Le Lem, P. Boullanger, G. Descotes, E. Wimmer, Bull. Soc. Chim. Fr. (3), 567 (1988)

17) Z. Cekovic, Z. Tokic, Synthesis 610 (1989)

${ }^{18)}$ H. A. Smith, J. Appl. Polym. Sci. 7, 85 (1963)

19) M. Ako, J. P. Kennedy, Polym. Bull. (Berlin) 19, 137 (1988)

20) (a) R. W. Lenz, "Organic Chemistry of Synthetic High Polymers": Interscience, New York, N. Y. 1967, and references therein; (b) L. H. Peebles, Macromolecules 7, 872 (1974)

21) J. W. Baker, J. B. Holdsworth, J. Chem. Soc. 713 (1947) 
22) S. Ephraim, A. E. Woodward, R. B. Mesrobian, J. Am. Chem. Soc. 80, 1326 (1958)

${ }^{23)}$ M. Sato, J. Am. Chem. Soc. 82, 3893 (1960)

${ }^{24)}$ R. G. Pearson, J. Polym. Sci., Polym. Chem. A25, 565 (1987)

${ }^{25)}$ E. Jacobi, H. Schuttenberg, R. C. Schulz, Makromol. Chem., Rapid Commun. 1, 397 (1980)

${ }^{26)}$ E. Biagini, E. Gattiglia, E. Pedemonte, S. Russo, Makromol. Chem. 184, 1213 (1983)

27) V. Darud, PhD Thesis, INSA de Lyon, 1988

28) L. Cuvé, J. P. Pascault, G. Boiteux, G. Seytre, Polymer 32, 343 (1991)

${ }^{29)}$ B. Fu, C. Feger, W. J. McKnight, N. S. Schneider, Polymer 26, 889 (1985)

30) T. G Fox, P. J. Flory, J. Appl. Phys. 21, 581 (1950) 